\title{
EXPERIMENTAL EVALUATION OF THE OUT-OF-PLANE BEHAVIOUR OF TRADITIONAL STONE MASONRY BUILDINGS IN AZORES, PORTUGAL
}

\author{
Arêde, António ${ }^{1}$, Costa, Aníbal ${ }^{2}$, Costa, Alexandre ${ }^{3 *}$, Ferreira, Tiago $^{2}$, \\ Gomes, Ana ${ }^{1}$ and Varum, Humberto ${ }^{2}$ \\ ${ }^{1}$ University of Porto, Faculty of Engineering \\ R. Dr. Roberto Frias, s/n, 4200-465, Porto, Portugal \\ e-mail: \{aarede,anazgomes\} @fe.up.pt \\ ${ }^{2}$ University of Aveiro \\ Campus Universitário de Santiago, 3810-193, Aveiro, Portugal \\ e-mail: \{agc,tmferreira,hvarum\}@ua.pt \\ ${ }^{3}$ School of Engineering, Polytechnic of Porto \\ R. Dr. António Bernardino de Almeida, 431, 4200-072, Porto, Portugal \\ e-mail: alc@isep.ipp.pt
}

Keywords: Stone Masonry, In-situ Tests, Seismic Behaviour, Out-of-plane, Strengthening.

\begin{abstract}
Recent earthquakes around the world, particularly those that have recently occurred in the southern regions of Europe, have provoked extensive damages in many traditional masonry structures calling into question the preservation and the safeguard of this heritage. This fact has driven the concern of the scientific community which has been undertaking several studies focused on the seismic vulnerability assessment of this type of structures, particularly in view of their rehabilitation and seismic strengthening/retrofitting.

In this context, this paper aims at presenting an in situ experimental test campaign recently carried out on an existing building abandoned after the 1998 Azores earthquake, in order to characterize the out-of-plane behavior of traditional masonry constructions. For testing purposes, an experimental test setup based on a self-equilibrated airbags system was used in the out-of-plane test of masonry piers under distinct conditions: original, retrofitted and strengthened.

An overall and brief discussion is included concerning the used test setup, in order to highlight their advantages and shortcomings. The system was found to be efficient for in-situ outof-plane testing of this type of thick (and massive) stone masonry walls, by applying distributed lateral loads which are agree better with actual inertia forces during seismic occurrence rather than top applied forces. The obtained results are presented and discussed focusing on the effectiveness of the retrofitting and/or strengthening solutions applied during the 1998 Azores reconstruction process. By comparing the results from the tested panels, such solutions were found to significantly increase the walls strength and energy dissipation capacity although not that much for the ultimate displacement.
\end{abstract}




\section{INTRODUCTION}

Stone masonry is one of the oldest building techniques used worldwide. Plus, if it is true that it can be considered as the simplest type of structure system concerning its assemblage, it is undeniable that, at the same time, it is one of the most complex construction materials in terms of mechanical properties and behaviour assessment. As a matter of fact, the behaviour of masonry structures under seismic excitations is clearly poor, calling into question the preservation of a valuable heritage which should be protected and safeguard.

Experimental studies are widely recognized as fundamental contributions for a correct characterization of structural components taking into account, for example, its constitution, behaviour, mechanical characteristics and so far. However, and despite the already mentioned value of this heritage, traditional stone masonry still remains with important lack of experimental characterization, particularly concerning its out-of-plane behaviour which is simultaneously one of the most common and most life-threatening collapse mechanisms.

In this context, the work herein presented aims at describing an experimental test campaign recently carried out in order to characterize the out-of-plane behaviour of traditional stone masonry constructions. Taking advantage of the abandon of some traditional masonry buildings after the earthquake that hit the Portuguese archipelago of Azores in 1998, three in-situ test were defined and performed with the application of quasi-static surface loads resorting to a self-equilibrated airbags' system. Bearing in mind the analysis of the retrofitting and/or strengthening solutions applied during the 1998 Azores reconstruction process, in terms of their real effectiveness, three masonry piers, under three distinct conditions: original, retrofitted and strengthened.

It is worth mentioning that this work arises in the sequence of some previous in-situ tests carried out by this research team on the study of the out-of-plane seismic resistance of traditional masonry structures (see [1, 2, 3]).

\section{IN-SITU EXPERIMENTS}

It is known that one of the main problems in testing existing masonry structures under laboratory-controlled environment lies on the correct reproduction of materials and assemblages. Despite this fact, vary few experimental works under in-situ conditions have been presented to date. In addition, most of the actual in-situ test setup do not guaranty that real service conditions are correctly reproduced (e.g. boundary conditions, acting loads, etc.). Therefore, the key issue of this work consisted on the definition and validation of an in-situ testing scheme that could be used on real masonry constructions, in a reliable way, according with three base requirements:

- Straightforward implementation;

- Reduced time for each test including a light and portable system;

- Possible to be used on the assessment of existing buildings under rehabilitation/strenghtening interventions.

\subsection{Description of the testing scheme}

The testing system used in this work was idealized to operate with simple and light components, avoiding external reaction elements. Thus, this test setup is based on a self-equilibrated action/reaction scheme making use of the existing elements in the main structure. The reaction frame used is composed by steel hollow rectangular elements and tubular steel elements with 
$60 \mathrm{~mm}$ of diameter to provide the connection between the reaction wall and the reaction frame. At the back of the airbag system and connected to the steel reaction frame, marine plywood planks were used (see Figure 1).
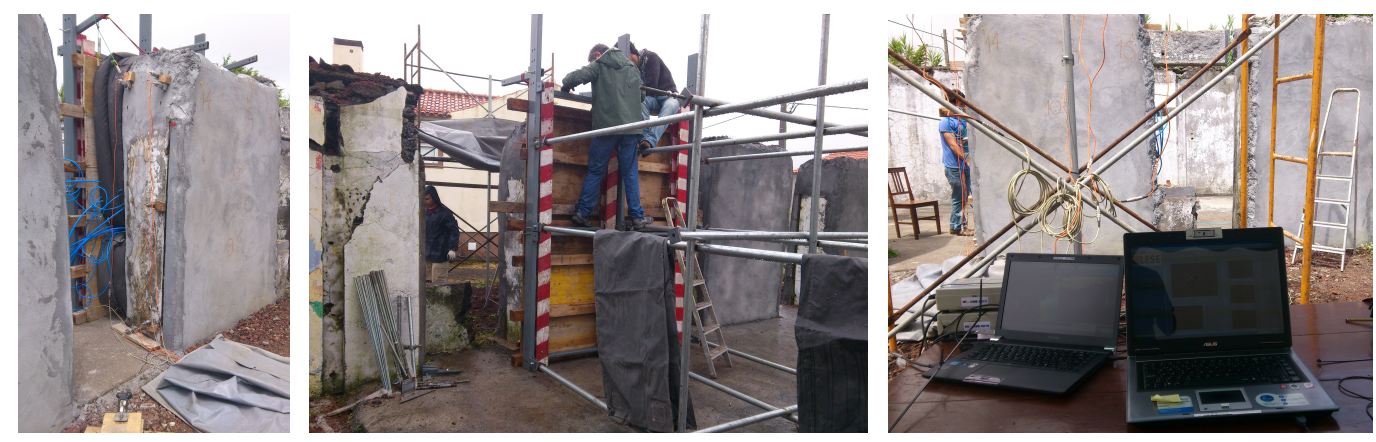

Figure 1: In-situ implementation for out-of-plane tests

Concerning the surface load, it was applied by means of six nylon airbags placed in two levels. The airbags are connected to an air compressor through a series of pipes $(\phi=8 \mathrm{~mm}$ and $\phi=14 \mathrm{~mm}$ ), which gradually inflated the airbags according to the loading history presented in Figure 2. During the tests, the pressure inside the airbags and the displacements of the masonry pier are monitored with pressure and displacement transducers (Linear Variable Displacement Transformers) properly connected to a portable data acquisition system.

It is worth noting that the application of distributed load resorting to an airbags system is not new (see for instance [4, 5]), However, the way how the test setup is implemented in this experimental campaign, associated with the original configuration of the reaction structure, which permits larger displacement levels, could constitute a step forward in the out-of-plane in-situ testing of full-scale masonry structures. Moreover, the capacity of this loading system to apply cyclic loads should also be highlighted.

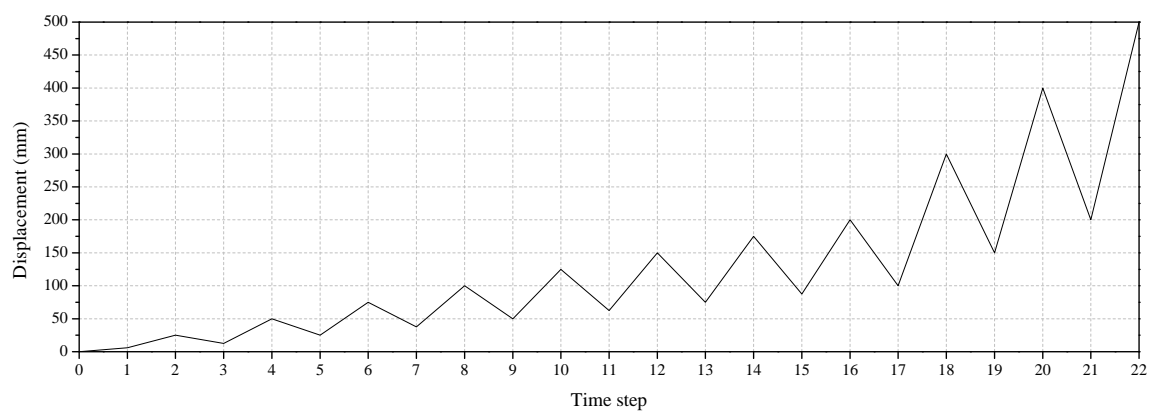

Figure 2: Loading history used in the airbag tests

\subsection{Characterization of the test elements}

As was already mentioned, a series of out-of-plane tests resorting to quasi-static surface loads was performed on three traditional masonry piers (sacco masonry), under different conditions: original, retrofitted and strengthened. Through this variation on the specimens' initial conditions, it was intended, not only to characterise their out-of-plane behaviour, but also to investigate the efficiency of some of the retrofitting and/or strengthening solutions that were widely applied after the 1998 earthquake that hit the Azores archipelago. According to this, the out-of-plane tests took place in an one-storey building, named herein as "Casa Nove", which 
can be considered representative of the traditional masonry construction in Portugal. Figure 3 presents an external view of the building as well as a schematic layout in which the three piers tested are highlighted. As can be seen in the figure, for presentation purposes, the masonry piers were named as $\mathrm{CN}-02 \mathrm{~S}, \mathrm{CN}-03 \mathrm{R}$ and $\mathrm{CN}-04$ where " $\mathrm{R}$ " stands to retrofit and "S" means strength.

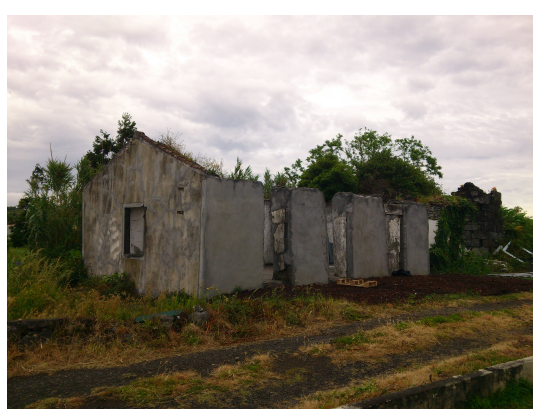

(a)

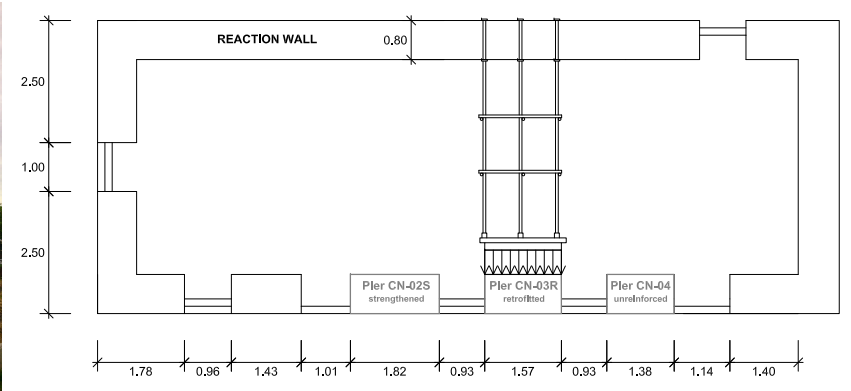

(b)

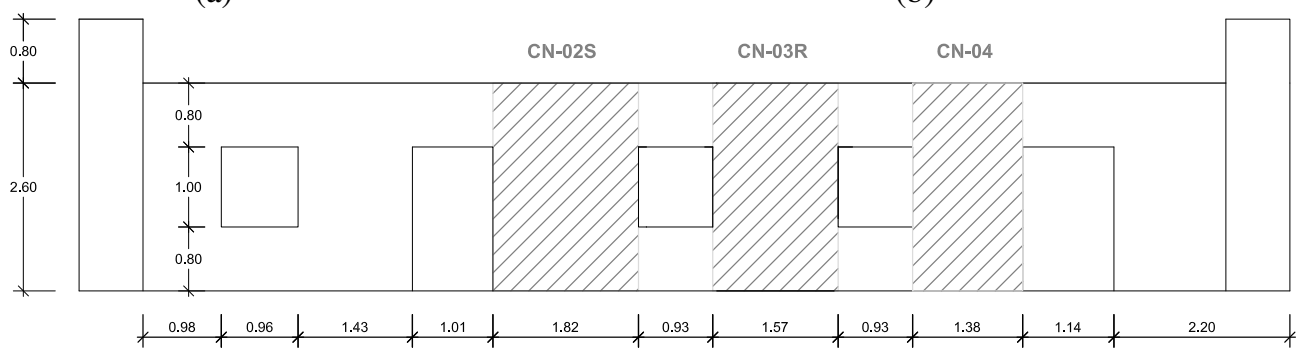

(c)

Figure 3: Building "Casa Nove": (a) external view of the building; (b) plan view; and (c) elevation

\section{STRENGTHENING AND RETROFITTING TECHNIQUES}

Developed in accordance with the recommendations of Carvalho et al. (1998)[6] and supported by Costa and Arêde (2006)[7], the strengthening scheme applied is based on the improvement of the connection between the two leafs that composes the walls section. Such improvement is achieved through the application of a reinforced plaster at both faces of the wall, properly connected by means of mechanical connectors. Figure 4 presents a section of the reinforced section as well as a picture of the moment when the application of the reinforcement was executed.

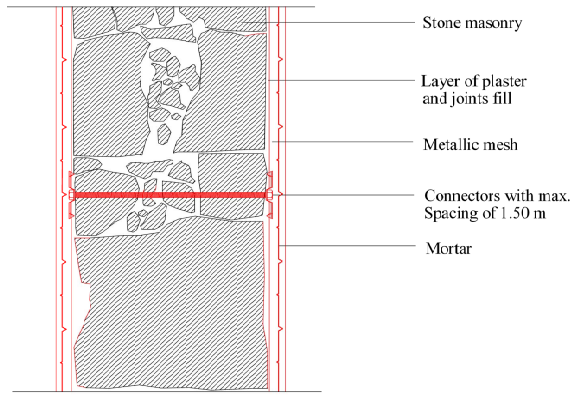

(a)

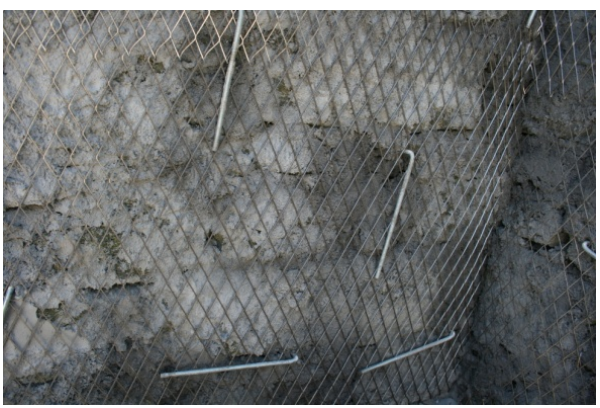

(b)

Figure 4: Wall strengthened with reinforced steel mesh: (a) schematic representation; and (b) execution of the reinforcement technique 
When this technique is applied prior to the earthquake (or damage due to the experimental test), it is considered as a strengthening scheme (CN-02S). However, if this technique is applied after the earthquake (or applied in a damaged specimen) it can be called as a retrofitting technique (CN-03R).

\section{RESULTS AND DATA INTERPRETATION}

The experimental data is presented on next in the form of load-displacement curves (Figures 7 (a)-5(a)), with key points from data summarized in Table 1 . It is worth mentioning that the following results were corrected by a correction factor which takes into account the effective pressure, correlated to the airbags' "opening". It is evident from the analysis of the figures, that such correction is particularly important in the range of large displacements. However, despite the importance of this aspect, its discussion is not within the scope of this paper (further considerations can be found in [2]).

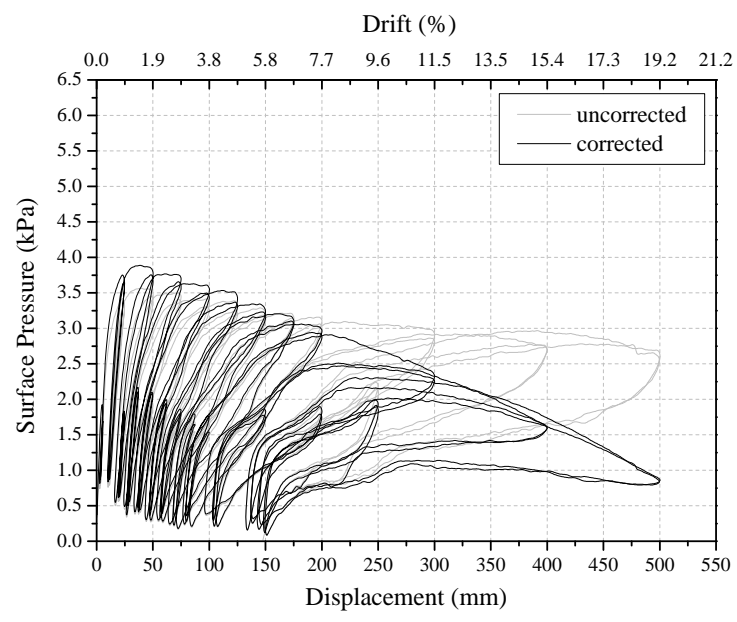

(a)

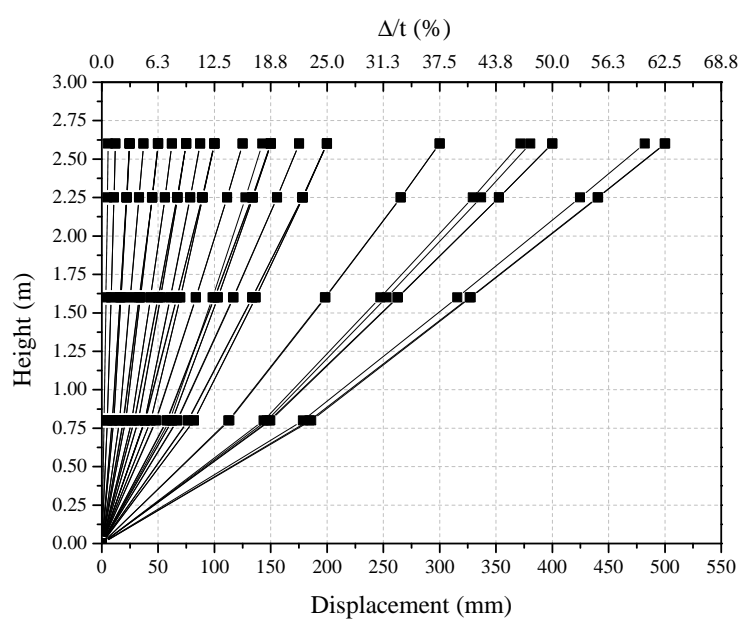

(b)

Figure 5: Wall CN-04: (a) Surface pressure vs displacement results; (b) height wise profiles of out-of-plane displacements

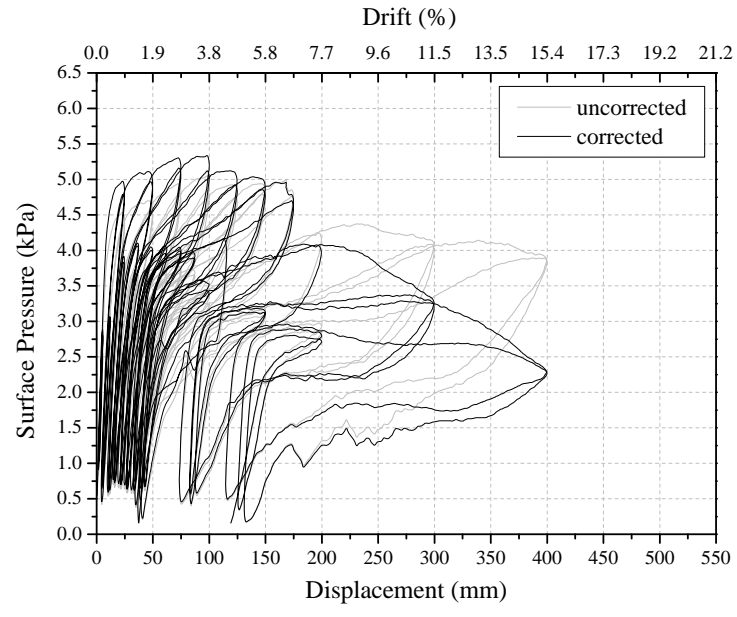

(a)

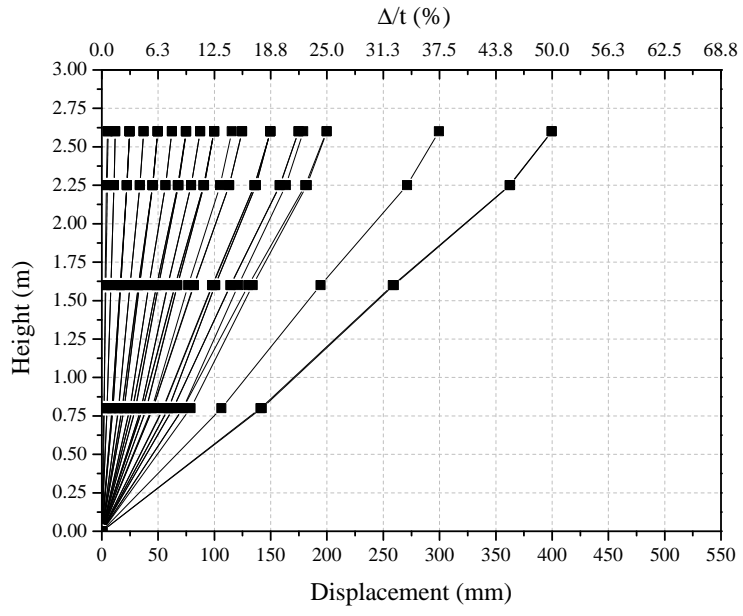

(b)

Figure 6: Wall CN-03R: (a) Surface pressure vs displacement results; (b) height wise profiles of out-of-plane displacements 


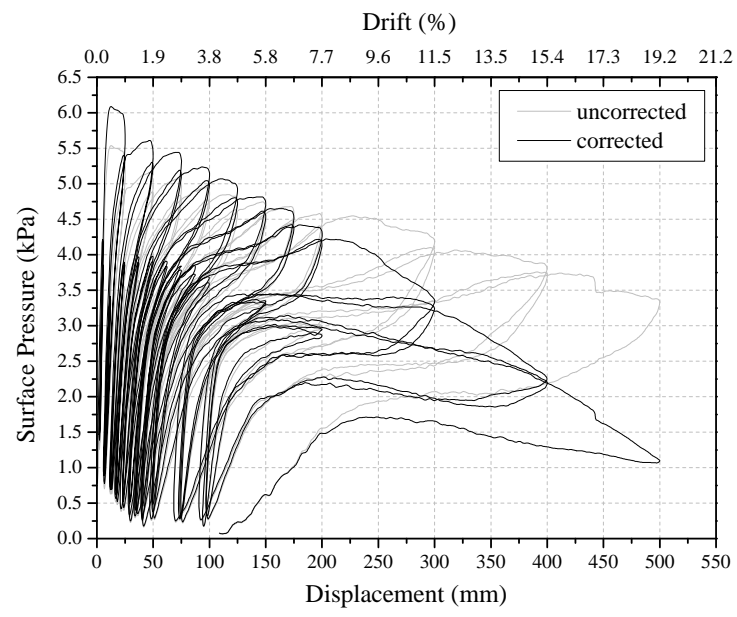

(a)

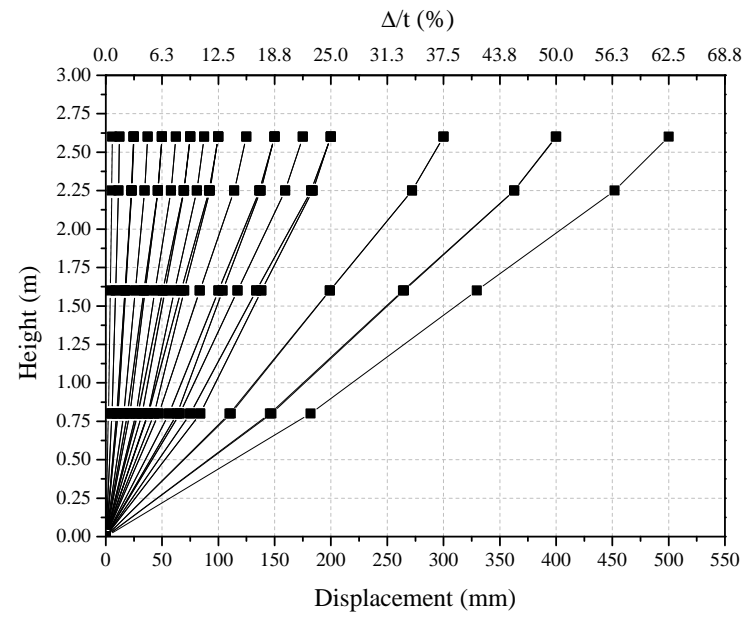

(b)

Figure 7: Wall CN-02S: (a) Surface pressure vs displacement results; (b) height wise profiles of out-of-plane displacements

As can be observed in Figure 7(a), the maximum strength of strengthened wall CN-02S was $6.12 \mathrm{kPa}$ which was reached at a displacement of $\Delta=11.76 \mathrm{~mm}$. This maximum strength value corresponds to an increase of about $14 \%$ when compared to the maximum strength obtained for the retrofitted wall CN-03R, with $5.37 \mathrm{kPa}$, and of about $57 \%$ in comparison with the value obtained for the unreinforced wall $\mathrm{CN}-04$, with $3.90 \mathrm{kPa}$ at a displacement of $\Delta=39.82 \mathrm{~mm}$ (see Table 1).

Figures 7(b)-5(b) present the height wise out-of-plane displacements' profiles obtained from the test. In general terms, its analysis shows that the test setup used was able to globally mobilize the out-of-plane response of the walls, which presented a flexural/rocking behaviour. As expected, and conditioned by the test setup which mobilizes the full height of the walls, the displacement profiles are quite similar among the three experimental tests. However, and as presented in Table 1, the displacement achieved at maximum strength is significantly different between the three experiments due to the adopted strengthening/retrofitting technique.

\begin{tabular}{|c|c|c|c|c|c|c|c|c|}
\hline \multirow[b]{2}{*}{ Wall } & \multicolumn{4}{|c|}{ At Maximum Strength } & \multicolumn{4}{|c|}{ At Maximum Displacement } \\
\hline & Surface Pressure $(\mathrm{kPa})$ & $\Delta(\mathrm{mm})$ & Drift (\%) & $\Delta / t(\%)$ & Surface Pressure $(\mathrm{kPa})$ & $\Delta(\mathrm{mm})$ & Drift (\%) & $\Delta / t(\%)$ \\
\hline $\mathrm{CN}-02 \mathrm{~S}$ & 6.12 & 11.76 & 0.45 & 1.47 & 1.09 & 500 & 19.23 & 62.50 \\
\hline $\mathrm{CN}-03 \mathrm{R}$ & 5.37 & 98.84 & 3.80 & 12.36 & 2.26 & 400 & 15.38 & 50 \\
\hline $\mathrm{CN}-04$ & 3.90 & 39.82 & 1.53 & 4.98 & 0.86 & 500 & 19.24 & 62.5 \\
\hline
\end{tabular}

Table 1: Summary of the surface pressure versus displacement results

Finally, Figure 8 (a) presents the envelope curves referring to the three experiments and Figure 8 (b) includes the curves of displacement versus energy dissipation reached during the tests. From both results, it is clear that walls $\mathrm{CN}-02 \mathrm{~S}$ and $\mathrm{CN}-03 \mathrm{R}$ present better energy dissipation capacity than the unreinforced wall CN-04. In fact, as can be seen in Figure 8(b), the strengthening technique used led to an increase of about $50 \%$ on energy dissipation capacity. Moreover, it can be observed a clear change of the energy curve trend at about $200 \mathrm{~mm}$, in accordance with the experimental results, which may be explained by a pure rigid body rotation around the base for this displacement level. 


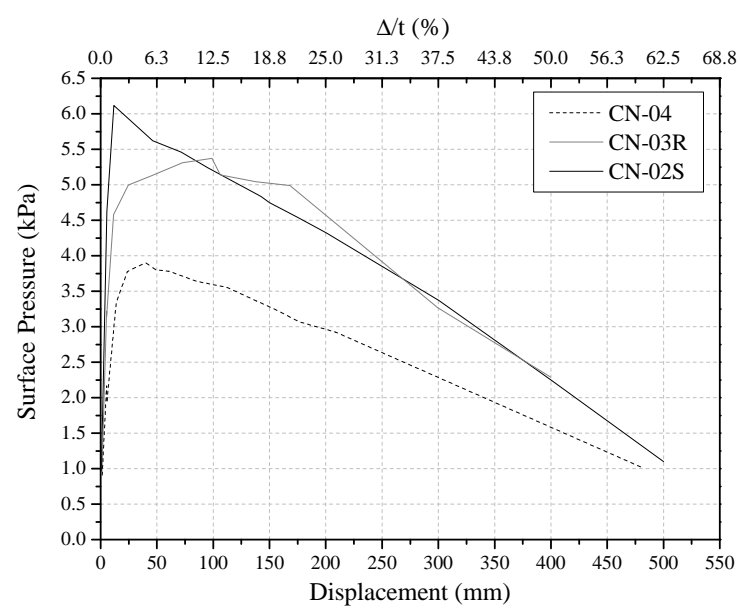

(a)

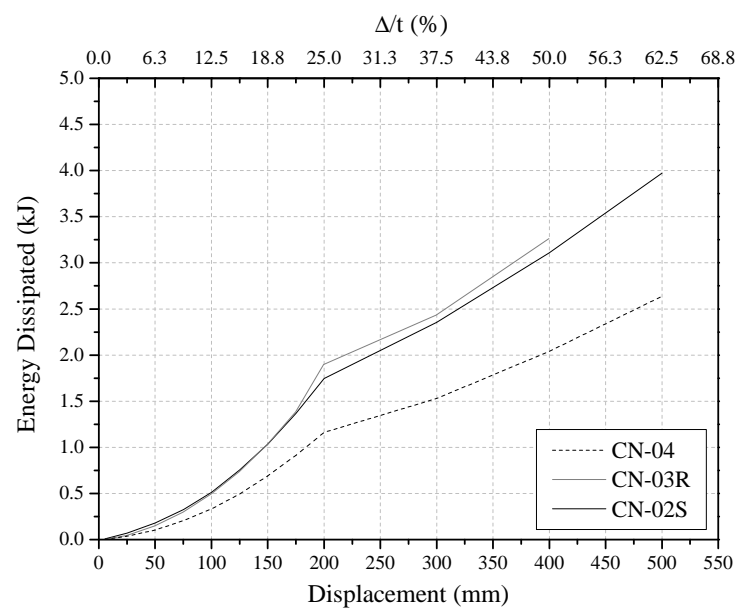

(b)

Figure 8: Comparison between experimental results: displacement vs (a) surface pressure; and (b) energy dissipated

It can be also highlighted that the three envelope curves trend to the same ultimate displacement for zero force, meaning that the strenthening/retrofit techniques may be more important for maximum strength and initial wall's behaviour rather than for ultimate displacement (for the wall's typology presented herein).

\section{FINAL REMARKS}

This work included a general overview of different topics focused on the experimental characterization of the out-of-plane behaviour of traditional stone masonry walls. Within this scope, an in-situ test setup was presented and validated through experimental data obtained from three in-situ tests performed in three stone masonry walls, under different conditions: original, retrofitted and strengthened. From the analysis of the results presented herein, two main conclusions can be pointed out:

(i) the test setup developed in the scope of this experimental campaign proved to be efficient on the in-situ out-of-plane testing of stone masonry walls;

(ii) the strengthening technique applied in two of the specimens, which consisted on the application of a reinforced plaster in both wall surfaces, led to a significative increase on the walls' strength and energy dissipation capacity.

\section{ACKNOWLEDGEMENTS}

This work refers to research made with a financial contribution of the Portuguese Foundation for Science and Technology (FCT). The authors' also knowledge the support of the Regional Government of Azores, through its Regional Secretariat for Tourism and Transport (RSTT), and the work of the technicians of the Laboratory of Earthquake and Structural Engineering (LESE) in the experimental activity reported.

\section{REFERENCES}

[1] Costa AA, Arêde A, Costa A, Oliveira C. In situ cyclic tests on existing stone masonry walls and strengthening solutions. Earthquake Engineering \& Structural Dynamics 2011; 
40(4):449-471, doi:10.1002/eqe.1046. URL http://dx.doi.org/10.1002/eqe. 1046 .

[2] Costa A, Costa AA, Arêde A, Garcia F, Ferreira T, Varum H. Out-of-plane in situ cyclic testing of unreinforced stone masonry walls with distributed loads. 15th IB2MaC, International Brick and Block Masonry Conference 2012; :17.

[3] Ferreira T, Vicente R, Varum H, Costa A, Costa AA. Out-of-plane seismic response of stone masonry walls: Experimental and analytical study of real piers. Proc. of the 15th World Conference on Earthquake Engineering, Lisbon, Portugal (CD-ROM), 2012.

[4] Griffith M, Vaculik J, Lam N, Wilson J, Lumantarna E. Cyclic testing of unreinforced masonry walls in two-way bending. Earthquake Engineering \& Structural Dynamics 2007; 36(6):801-821.

[5] Dizhur D, Derakhshan H, Ingham J, Griffith M. In-situ out-of-plane testing of an unreinforced masonry partition walls. 11th Canadian Masonry Symposium, Toronto, 2009.

[6] Carvalho E, Oliveira C, Fragoso M, Miranda V. Regras gerais de reabilitação e reconstrução de edifícios correntes afectados pela crise sísmica do faial, pico e s. Jorge iniciada pelo sísmo de 9 de Julho de 1998. Technical Report, Lisboa 1998.

[7] Costa A, Arêde A. Strengthening of structures damaged by the Azores earthquake of 1998 . Construction and Building Materials 2006; 20(4):252-268, doi:10.1016/j.conbuildmat. 2005.08.029. 